\title{
TEMU LAMPUNG BERASIS WEBSITE UNTUK MEMPERMUDAH PENCARIAN TEMPAT WISATA SERTA PEMANDU WISATA DI LAMPUNG
}

\author{
Fenty Ariani $^{\# 1}$, Theresia Cathline Adelia ${ }^{* 2}$, Yuthsi Aprilinda ${ }^{* 3}$, Ayu Kartika Puspa ${ }^{\# 4}$ \\ Fakultas Ilmu Komputer \\ ${ }^{I}$ Program Studi Sistem Informasi \\ ${ }^{3}$ Program Studi Informatika \\ Universitas Bandar Lampung \\ Jl. ZA Pagar Alam No 26 Labuhan Ratu Bandar Lampung \\ Iaureliacathlinelgmail.com \\ fenty.arianidubl.ac.id \\ 3 yuthsi.aprilindalubl.ac.id \\ 4ayukartikapuspa@ubl.ac.id
}

\begin{abstract}
Abstrak
Lampung adalah sebuah provinsi paling selatan di Pulau Sumatra. Letak geografis Lampung yang di sebelah barat berbatasan dengan Selat Sunda dan sebelah timur dengan Laut Jawa, membuat provinsi ini dikelilingi oleh berbagai wisata alam berupa pantai, dan lainnya yang tak kalah menarik dengan wilayah lain di Indonesia. Selain wisata alam berupa pantai, gunung, bukit, dsb, Lampung juga terkenal dengan Pusat penangkaran dan pelatihan gajah di Taman Nasional Way Kambas, sehingga dikenal juga sebagai Kota Gajah. Namun sayangnya, dengan segala kekayaan yang dimiliki oleh Lampung, kurang diimbangi dengan jumlahnya pengetahuan para turis terhadap kekayaan daerah ini. Penulis merancang suatu website yaitu website Temu Lampung, yang bertujuan untuk membantu dan memudahkan turis yang datang dari berbagai macam daerah untuk dapat lebih mudah melakukan pencarian tempat wisata serta pemandu wisata (tour guide) di Lampung.
\end{abstract}

Kata kunci: Website, Pemadu Wisata, Tempat Wisata, Lampung, Pariwisata.

\section{Pendahuluan}

Indonesia memiliki kekayaan alam dan keindahan alam yang berlimpah, di setiap kota yang terletak di Indonesia memiliki keindahan alam tersendiri. Keindahan alam yang dimiliki suatu daerah dapat dijadikan suatu tempat wisata. Tingkat pemasukan Indonesia dari sektor pariwisata juga semakin meningkat dari tahun ke tahunnya, semakin banyak turis domestik maupun turis mancanegara yang mengunjungi berbagai macam tempat wisata di Indonesia.

Provinsi Lampung juga memiliki daya tarik di sektor pariwisatanya. Lampung memiliki banyak lokasi pantai yang dapat menarik perhatian para turis, namun kurangnya informasi dan akses yang sulit untuk mencapai lokasi wisata tersebut, membuat lokasi wisata di Provinsi Lampung kurang diketahui oleh para turis. Selain itu, pemandu wisata (tour guide) juga penting bagi para turis, di karenakan ketidak tahuan mengenai daerah Lampung, maka dari itu banyak turis yang membutuhkan jasa pemandu wisata juga, namun sekarang masih sulit di temukan pemandu wisata untuk di daerah Provinsi Lampung. Kesulitan para turis untuk menemukan pemandu wisata salah satunya disebabkan oleh kurangnya wadah yang memfasilitasi untuk bertemunya turis dengan pemandu wisata.
Dengan berkembangnya teknologi saat ini, banyak hal yang dapat di manfaatkan untuk mempromosikan tempat wisata di Provinsi Lampung. Penggunaan website untuk membantu mengenalkan pariwisata di Provinsi Lampung adalah salah satu cara untuk memanfaatkan perkembangan teknologi tersebut. Para pemandu wisata dapat mendaftar pada website tersebut untuk mempromosikan jasanya. Selain itu, akan terdapat fitur bagi para turis untuk dapat memilih pemandu wisata yang sesuai dengan kriteria yang sesuai dengan pilihannya. Hal ini dapat mempermudah para turis yang ingin mengunjungi Provinsi Lampung.

\subsection{Identifikasi Masalah}

Berdasarkan latar belakang masalah di atas maka penulis mendapatkan beberapa masalah sebagai berikut:

a. Lokasi wisata di Lampung yang belum diketahui oleh para turis domestik maupun turis mancanegara.

b. Kurangnya media informasi untuk mendapatkan pemandu wisata (tour guide) di daerah wisata. 


\subsection{Rumusan Masalah}

Rumusan masalah dari penelitian ini yaitu:

a. Apakah website tersebut dapat membantu turis menemukan lokasi wisata beserta pemandu wisata untuk di daerah wisata Lampung?

b. Bagaimana cara pemandu wisata mempromosikan jasanya?

c. Bagaimana cara user dapat menemukan pemandu wisata yang sesuai dengan keinginannya?

\section{Landasan Teori}

\subsection{Pengertian Website}

Website memiliki beberapa pengertian yang berbeda. Website adalah keseluruhan halamanhalaman web yang terdapat dalam sebuah domain yang mengandung informasi.(Ariani, F, 2018). Website adalah media penyampai informasi di internet. Website dibentuk dan diciptakan dari serangkaian script atau kode tertentu dari bahasa pemrogaman tertentu. (Jovan, 2007). Jadi, website adalah salah satu aplikasi yang berisiskan dokumendokumen multi media (teks, gambar, suara, animasi, video) didalamnya yang menggunakan protocol HTTP (hypertext transfer protocol) dan untuk mengaksesnya menggunakan perangkat lunak yang disebut browser. Terdapat berbagai macam jenis browser, seperti Google Chrome, Mozilla Firefox, Safari, dsb. Browser (perambah) sendiri adalah aplikasi yang mampu menjalankan dokumendokumen web dengan cara diterjemahkan. Prosesnya dilakukan oleh komponen yang terdapat didalam aplikasi browser yang biasa disebut web engine. Semua dokumen web ditampilkan oleh Browser dengan cara diterjemahkan.

Ditinjau dari aspek Content atau isi, website dapat dibagi menjadi 2 jenis, yaitu website statis (web statis) dan website dinamis (web dinamis). Selain dilihat dari sisi content/isi, website statis dan website dinamis dapat dilihat dari aspek teknologi yang digunakan untuk membuat jenis website tersebut.

Web statis adalah web yang isinya/ content tidak berubah-ubah. Maksudnya adalah isi dari dokumen web tersebut tidak dapat diubah secara cepat dan mudah. Ini karena teknologi yang digunakan untuk membuat dokumen web ini tidak memungkinkan dilakukan perubahan isi/data. Teknologi yang digunakan untuk web statis adalah jenis client side scripting seperti HTML, Cascading Style Sheet (CSS). Perubahan isi/data pada halaman web statis hanya dapat dilakukan dengan cara mengubah langsung isinya pada filementah web tersebut. Misalkan jika sebuah dokumen web dibuat menggunakan script HTML maka perubhan isi dilakukan dengan cara membuka dokumen file tersebut (yang berekstensi HTML) lalu isinya diganti langsung di dokumen web tersebut. Untuk melakukannya diperlukan pengetahuan yang cukup tentang client side scripting atau dengan kata lain hanya dapat dilakukan oleh seorang programmer web yang menguasai perintah-perintah client side scripting. Jika dokumen web sudah diunggah di internet, maka perubahan dilakukan dengan cara membuka file dokumen tersebut di komputer local secara offline untuk selanjutnya diganti isinya. Hasil perubahannya kemudian disimpan dan diunggah kembali ke internet. Contoh web statis diantaranya adalah web profil perusahaan yang lebih dominan menggunakan anamasi Flash atau HTML, web kumpulan produk animasi.

Web dinamis adalah jenis web yang content/isi dapat berubah-ubah setiap saat. Web yang banyak menampilkan animasi flash belum tentu termasuk web dinamis karena dinamis/berubah-ubah isinya tidak sama dengan animasi. Untuk melakukan perubahan data, user cukup mengubahnya langsung secara online di internet melalui halaman control panel/administrasi yang biasanya telah disediakan untuk user administrator sepanjang user tersebut memiliki hak akses yang sesuai. Fitur yang disediakan untuk melakukan pengolahan terhadap content/isi halaman web dinamis biasanya dibuat semudah mungkin, karena user yang akan melakukan perubahan data di halaman web tersebut kemungkinan bukanlah user yang menguasai detail teknis bahasa pemrograman dan database atau biasa di istilahkan user biasa. Untuk membuat web dinamis diperlukan beberapa komponen yaitu client side scripting seperti. PHP, program basis data seperti MySQL untuk menyimpan data-datanya. Contoh situs web dinamis banyak sekali diinternet, diantaranya: situs web berita, situs web $E$ Commerce, situs web e-Banking. (Arief, 2011)

\subsection{Pengertian PHP}

PHP (PHP: Hypertext apareprocessor) adalah sebuah bahasa pemrogaman scripting untuk membuat halaman web yang dinamis. Walaupun dikenal sebagai bahasa untuk membuat halaman web, tapi PHP se-benarnya juga dapat digunakan untuk membuat aplikasi command line dan juga GUI. Cara kerja PHP adalah menyelipkannya di antara kode HTML (hypertext markup language), karena itu di modul pertama ini kita akan belajar sedikit HTML. Website yang dibuat menggunakan PHP memerlukan software bernama webserver tempat pemrosesan kode PHP dilakukan. Software web yang memiliki software PHP Parser akan memproses input berupa kode PHP dan menghasilkan output berupa halaman web. (Ali Zaki, 2008)

PHP termasuk dalam Open Source Product, sehingga source code PHP dapat diubah dan didistribusikan secara bebas. Versi terbaru PHP dapat diunduh secara gratis di situs resmi PHP: http://www.php.net. PHP juga dapat berjalan pada berbagai web server seperti IIS ( Internet Information Server), PWS (Personal Web Server), Apache, Xitami. PHP juga mampu lintas platform. Artinya PHP dapat berjalan dibanyak sistem operasi 
yang beredar saat ini, di antaranya : Sistem Operasi Microsoft Windows (semua versi), Linux, Mac OS, Solaris. PHP dapat dibangun sebagai modul pada web server Apache dan sebagai binary yang dapat berjalan sebagai CGI (Common Gateway Interface). PHP dapat mengirim HTTP header, dapat mengatur cookies, mengatur authentication dan redirect user.

Salah satu keunggulan yang dimiliki oleh PHP adalah kemampuannya untuk melakukan koneksi keberbagai macam software sistem manajemen basis data/Database Management System (DBSM), sehingga dapat menciptakan suatu halaman web yang dinamis. PHP mempunyai koneksitas yang baik dengan beberapa DBSM antara Oracle, Sybase, mSQL, MySQL, Microsoft SQL Server, Solid, PostgreSQL, Adabas, FilePro, Velocis, dBase, Unix $\mathrm{dbm}$, dan tak terkecuali semua database berinterface ODBC. PHP juga memiliki integrasi dengan beberapa library eksternal yang dapat membuat anda melakukan segalanya dari dokumen PDF hingga mem-parse XML. PHP mendukung komunikasi dengan layanan lain melalui protocol IMAP, SNMP, NNTP, POP3, atau bahkan HTTP. Bila PHP berada dalam halaman web anda, maka tidak lagi dibutuhkan pengembangan lingkungan khusus atau direktori khusus. Hampir seluruh aplikasi berbasis web dapat dibuat dengan PHP. Namun kekuatan utama adalah konektivitas basis data dengan web. Dengan kemampuan ini kita akan mempunyai suatu sistem basis data yang dapat diakses dari web. (Arief, 2011)

\subsection{Pengertian Database}

Database adalah sebuah struktur yang umumnya terbagi dalam 2 hal, yaitu sebuah database flat dan sebuah database relasional. Database relasional lebih mudah dipahami daripada database flat karena database relasional mempunyai bentuk yang sederhana serta mudah dilakukan operasi data. Database yang memiliki struktur relasional terdapat tabel-tabel untuk menyimpan data. Pada setiap tabelterdiri dari kolom dan baris serta sebuah kolom untuk mendefinisikan jenis informasi apa yang harus disimpan. (Komputer, 2010)

\section{Metode Penelitian}

Dalam sebuah penelitian hal terpenting yang harus ada yaitu metode. Metode sendiri berasal dari bahasa Yunani yaitu methos yang artinya cara atau jalan. Secara umum metode penelitian diartikan sebagai cara ilmiah untuk mendapatkan data dengan tujuan dan kegunaan tertentu. (Sugiyono, 2012) Jika dilihat dalam Kamus Besar Bahasa Indonesia, metode dapat diartikan sebagai cara teratur yang digunakan untuk melaksanakan suatu pekerjaan agar tercapai sesuai dengan yang dikehendaki. Pentingnya menggunakan metode penelitian dalam sebuah penelitian untuk menunjang segala hasil penelitian yang ada, karena metode penelitian berkaitan dengan prosedur, teknik, alat, serta desain penelitian yang digunakan untuk memahami objek yang menjadi sasaran ilmu yang bersangkutan yang sedang diteliti.

\subsection{Metode Pengumpulan Data}

Pada penelitian ini, menggunakan 3 (tiga) metode pengumpulan data, yakni sebagai berikut:

\subsubsection{Studi Literatur}

Pada studi literatur, penulis menggunakan beberapa jurnal ilmiah dan berbagai macam artikel di internet sebagai refrensi penulis.

\subsubsection{Studi Pustaka}

Pada studi pustaka, penulis mencari informasiinformasi dari beberapa buku guna mendukung landasan teori dalam penelitian ini.

\subsubsection{Studi Lapangan}

Observasi yang dilakukan oleh penulis adalah mencari orang-orang yang mengetahui tentang satu atau lebih lokasi wisata yang telah menjadi pemandu wisata di Lampung. Kemudian penulis juga menyebar kuisioner (angket) pre-test dan posttest kepada para turis yang sudah pernah ataupun belum pernah mengunjungi Lampung. Angket menurut KBBI adalah daftar pertanyaan tertulis mengenai masalah tertentu dengan ruang untuk jawaban bagi setiap pertanyaan.

\subsection{Analisis Kebutuhan}

\subsubsection{Kebutuhan Perangkat Lunak}

Perangkat lunak yang digunakan dalam perancangan aplikasi agar program yang dirancang dapat berjalan dengan baik sebagai berikut:

\begin{tabular}{|r|l|l|}
\hline \multicolumn{1}{|c|}{ No. } & \multicolumn{1}{|c|}{ Client } & \multicolumn{1}{c|}{ Software } \\
\hline 1 & Sistem Operasi & Windows 10 \\
\hline 2 & Database & MySQL \\
\hline 3 & Server & XAMPP \\
\hline 4 & Software Development & Sublime Text \\
\hline 5 & Browser & Google Chrome \\
\hline
\end{tabular}

\subsubsection{Kebutuhan Perangkat Keras}

Perangkat keras yang yang digunakan dalam perancangan aplikasi memiliki spesifikasi sebagai berikut:

\begin{tabular}{|c|l|l|}
\hline No. & Hardware & Laptop \\
\hline 1 & Processor & Intel(R) Core(TM) i3 \\
\hline 2 & RAM & $4 \mathrm{~GB}$ \\
\hline 3 & Memory & $1 \mathrm{~GB}$ \\
\hline
\end{tabular}




\subsection{Perancangan Penelitian}

\subsubsection{Use Case}

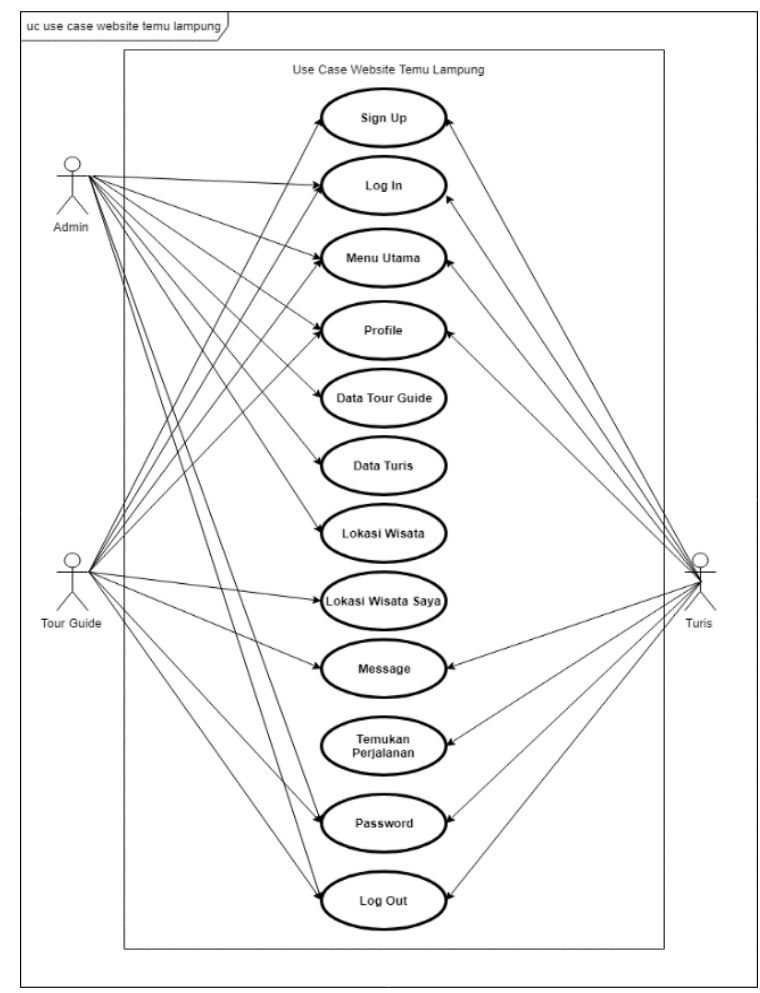

\subsubsection{Sequence Diagram}

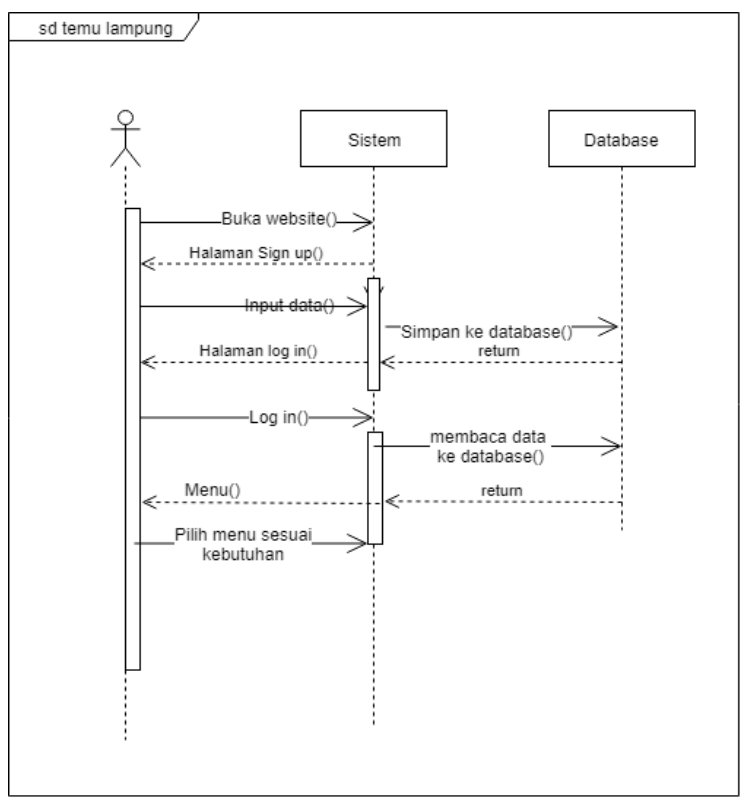

\subsubsection{Activity Diagram}

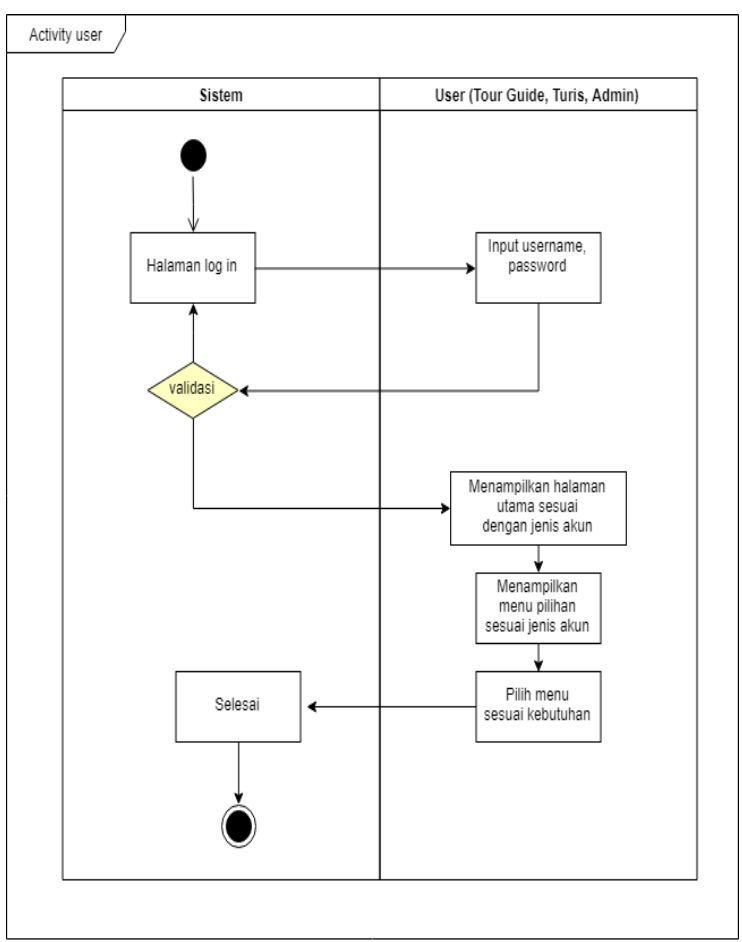

\subsubsection{Flowchart}

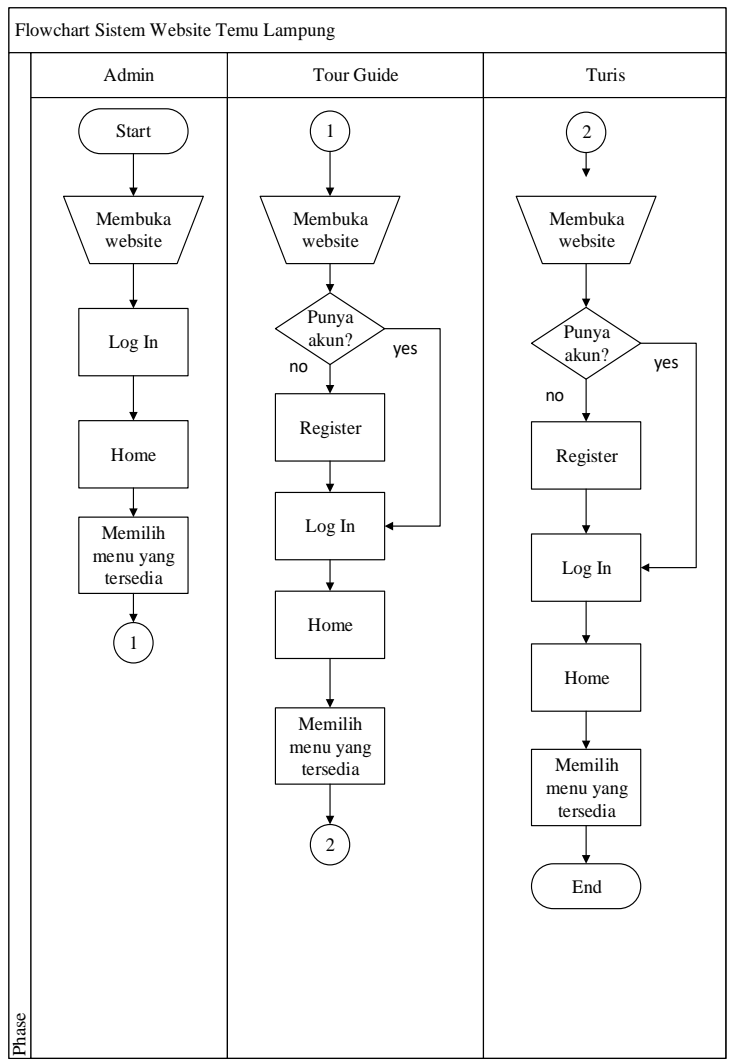




\subsection{Rancangan Tampilan}

\subsubsection{Rancangan Tampilan Utama}

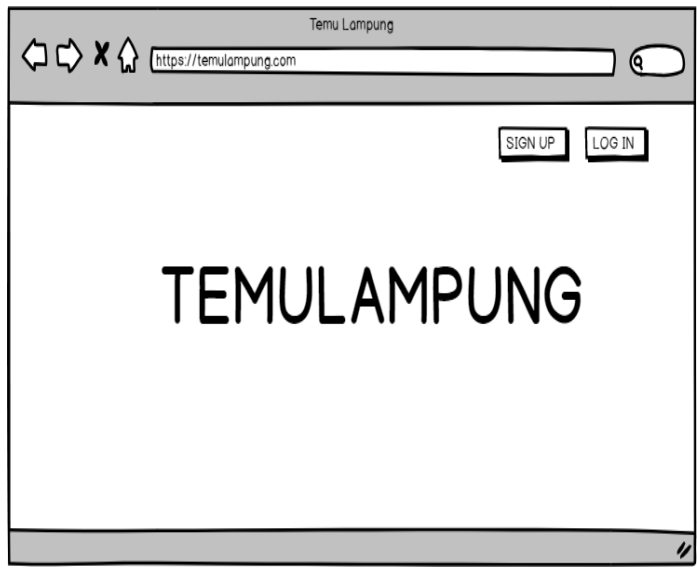

\subsubsection{Rancangan Tampilan Log In}

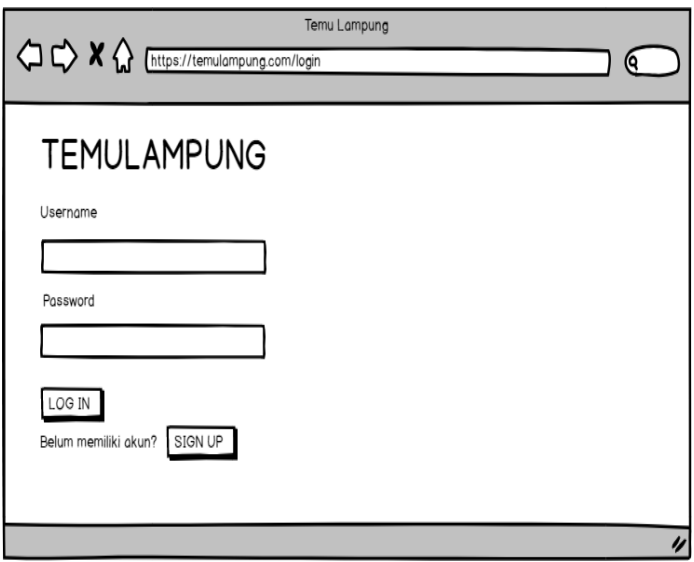

\subsubsection{Rancangan Tampilan Sign Up}

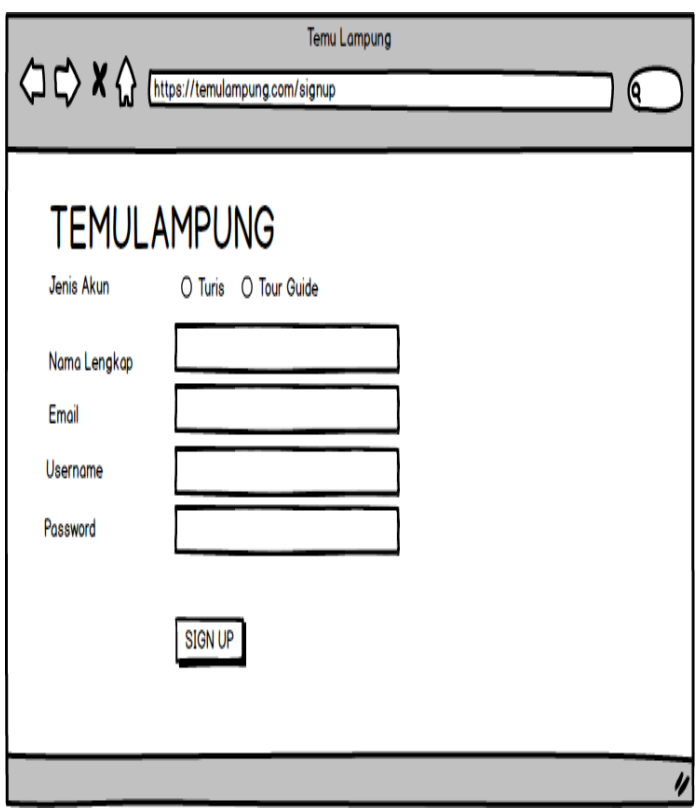

3.4.4. Rancangan Tampilan Home Turis

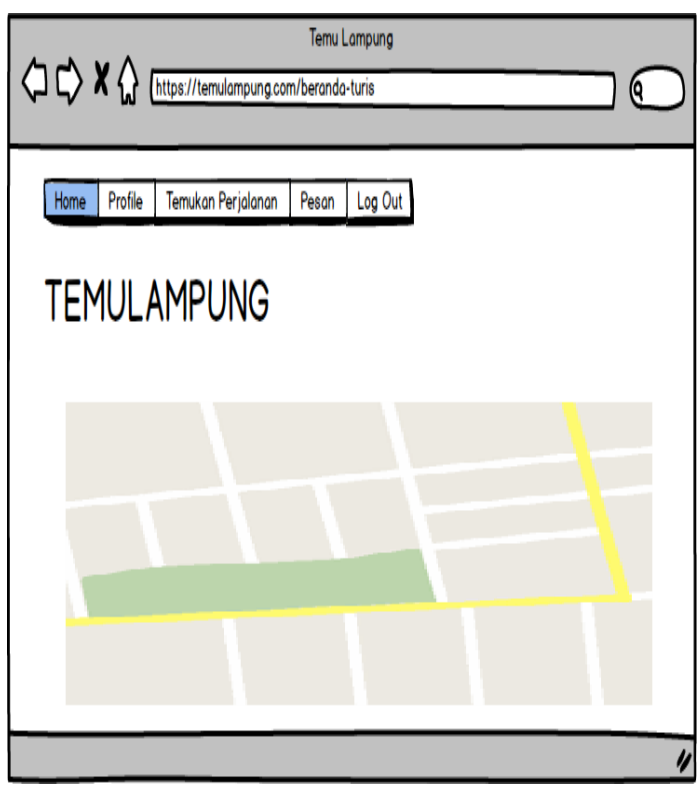

3.4.5. Rancangan Tampilan Home Tour Guide

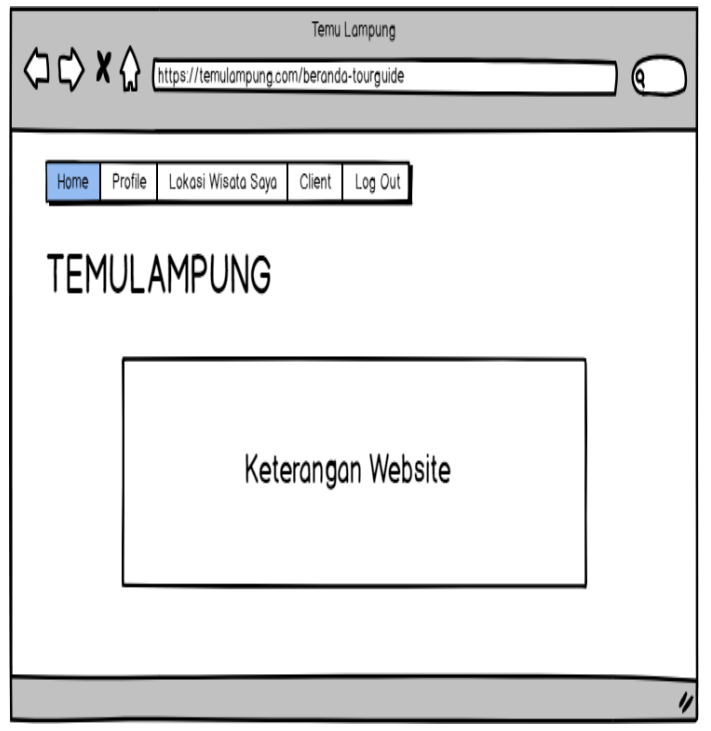

\section{Pembahasan}

\subsection{Cara Kerja Website}

Website dapat diakses pada www.temulampung.com, kemudian user dapat membuat akun sesuai dengan kebutuhan. Terdapat dua jenis akun yang dapat dibuat, yaitu: turis dan tourguide. Sebagai tourguide dapat input lokasi yang diketahui, kemudian lokasi tersebut akan muncul pada halaman akun turis dan dapat dilakukan proses booking dengan cara, seorang turis dapat memilih lokasi wisata, tour guide, dan satu tanggal perjalanan, jika tanggal tersebut sudah terisi oleh turis lain, maka sistem akan secara otomatis menolak request tersebut. Antar turis dan tourguide dapat berkomunikasi juga dengan fitur message yang tersedia. 
4.2. Pengujian Black Box

4.2.1. Halaman Utama

\begin{tabular}{|c|c|c|c|c|}
\hline No & $\begin{array}{l}\text { Skenario } \\
\text { Pengujian }\end{array}$ & $\begin{array}{l}\text { Hasil yang } \\
\text { diharapkan }\end{array}$ & $\begin{array}{l}\text { Hasil } \\
\text { yang } \\
\text { didapatka } \\
\mathrm{n}\end{array}$ & $\begin{array}{l}\text { Temuan } \\
\text { Kesesuai } \\
\text { an }\end{array}$ \\
\hline 1 & $\begin{array}{l}\text { Klik nav } \\
\text { bar about }\end{array}$ & $\begin{array}{l}\text { Menampilk } \\
\text { an bagian } \\
\text { about }\end{array}$ & $\begin{array}{l}\text { Tampil } \\
\text { bagian } \\
\text { about }\end{array}$ & Sesuai \\
\hline 2 & $\begin{array}{l}\text { Klik nav } \\
\text { bar } \\
\text { keunggul } \\
\text { an kami } \\
\end{array}$ & $\begin{array}{l}\text { Menampilk } \\
\text { an bagian } \\
\text { keunggulan } \\
\text { kami }\end{array}$ & $\begin{array}{l}\text { Tampil } \\
\text { bagian } \\
\text { keunggul } \\
\text { an kami }\end{array}$ & Sesuai \\
\hline 3 & $\begin{array}{l}\text { Klik nav } \\
\text { bar lokasi } \\
\text { wisata }\end{array}$ & $\begin{array}{l}\text { Menampilk } \\
\text { an bagian } \\
\text { lokasi } \\
\text { wisata }\end{array}$ & $\begin{array}{l}\text { Tampil } \\
\text { bagian } \\
\text { lokasi } \\
\text { wisata }\end{array}$ & Sesuai \\
\hline 4 & $\begin{array}{l}\text { Klik nav } \\
\text { bar maps }\end{array}$ & $\begin{array}{l}\text { Menampilk } \\
\text { an bagian } \\
\text { maps }\end{array}$ & $\begin{array}{l}\text { Tampil } \\
\text { bagian } \\
\text { maps }\end{array}$ & Sesuai \\
\hline 5 & $\begin{array}{l}\text { Klik } \\
\text { marker } \\
\text { pada } \\
\text { maps }\end{array}$ & $\begin{array}{l}\text { Menampilk } \\
\text { an nama } \\
\text { lokasi dan } \\
\text { alamat }\end{array}$ & $\begin{array}{l}\text { Tampil } \\
\text { nama } \\
\text { lokasi } \\
\text { dan } \\
\text { alamat }\end{array}$ & Sesuai \\
\hline 6 & $\begin{array}{l}\text { Klik nav } \\
\text { bar log } \\
\text { in/sign up }\end{array}$ & $\begin{array}{l}\text { Menampilk } \\
\text { an bagian } \\
\log \text { in/sign } \\
\text { up }\end{array}$ & $\begin{array}{l}\text { Tampil } \\
\text { bagian } \\
\text { log } \\
\text { in/sign up }\end{array}$ & Sesuai \\
\hline 7 & $\begin{array}{l}\text { Klik } \\
\text { button } \\
\log \text { in }\end{array}$ & $\begin{array}{l}\text { Menampilk } \\
\text { an halaman } \\
\text { log in }\end{array}$ & $\begin{array}{l}\text { Tampil } \\
\text { halaman } \\
\text { log in }\end{array}$ & Sesuai \\
\hline 8 & $\begin{array}{l}\text { Klik } \\
\text { button } \\
\text { sign up }\end{array}$ & $\begin{array}{l}\text { Menampilk } \\
\text { an halaman } \\
\text { sign up }\end{array}$ & $\begin{array}{l}\text { Tampil } \\
\text { halaman } \\
\text { sign up }\end{array}$ & Sesuai \\
\hline
\end{tabular}

4.2.2. Halaman Log In

\begin{tabular}{|c|c|c|c|c|}
\hline $\begin{array}{l}\text { No } \\
\text {. }\end{array}$ & $\begin{array}{l}\text { Skenari } \\
\text { o } \\
\text { Penguji } \\
\text { an } \\
\end{array}$ & $\begin{array}{l}\text { Hasil yang } \\
\text { Diharapka } \\
\text { n }\end{array}$ & $\begin{array}{l}\text { Hasil } \\
\text { yang } \\
\text { Didapatk } \\
\text { an } \\
\end{array}$ & $\begin{array}{l}\text { Temuan } \\
\text { Kesesuai } \\
\text { an }\end{array}$ \\
\hline 1. & $\begin{array}{l}\text { Input } \\
\text { usernam } \\
\mathrm{e}\end{array}$ & $\begin{array}{l}\text { Menampilk } \\
\text { an } \\
\text { username }\end{array}$ & $\begin{array}{l}\text { Tampil } \\
\text { username } \\
\text { yang } \\
\text { sudah } \\
\text { diinput }\end{array}$ & Sesuai \\
\hline 2. & $\begin{array}{l}\text { Input } \\
\text { passwor } \\
d\end{array}$ & $\begin{array}{l}\text { Menampilk } \\
\text { an } \\
\text { password }\end{array}$ & $\begin{array}{l}\text { Tampil } \\
\text { password } \\
\text { yang } \\
\text { sudah } \\
\text { diinput }\end{array}$ & Sesuai \\
\hline 3. & $\begin{array}{l}\text { Klik } \\
\text { button } \\
\log \text { in }\end{array}$ & $\begin{array}{l}\text { Masuk ke } \\
\text { halaman } \\
\text { yang sesuai } \\
\text { dengan } \\
\text { jenis akun } \\
\text { saat sign up }\end{array}$ & $\begin{array}{l}\text { Tampil } \\
\text { halaman } \\
\text { utama } \\
\text { sesuai } \\
\text { jenis akun }\end{array}$ & Sesuai \\
\hline 4. & $\begin{array}{l}\text { Klik link } \\
\text { lupa } \\
\text { passwor } \\
\text { d } \\
\end{array}$ & $\begin{array}{l}\text { Menampilk } \\
\text { an halaman } \\
\text { lupa } \\
\text { password }\end{array}$ & $\begin{array}{l}\text { Tampil } \\
\text { halaman } \\
\text { lupa } \\
\text { password }\end{array}$ & Sesuai \\
\hline 5. & $\begin{array}{l}\text { Klik link } \\
\text { sign up }\end{array}$ & $\begin{array}{l}\text { Menampilk } \\
\text { an halaman } \\
\text { sign up }\end{array}$ & $\begin{array}{l}\text { Tampil } \\
\text { halaman } \\
\text { sign up }\end{array}$ & Sesuai \\
\hline 6. & $\begin{array}{l}\text { Klik nav } \\
\text { bar } \\
\text { home }\end{array}$ & $\begin{array}{l}\text { Menampilk } \\
\text { an halaman } \\
\text { home }\end{array}$ & $\begin{array}{l}\text { Tampil } \\
\text { halaman } \\
\text { home }\end{array}$ & Sesuai \\
\hline 7. & $\begin{array}{l}\text { Klik nav } \\
\text { bar sign } \\
\text { up }\end{array}$ & $\begin{array}{l}\text { Menampilk } \\
\text { an halaman } \\
\text { sign up }\end{array}$ & $\begin{array}{l}\text { Tampil } \\
\text { halaman } \\
\text { sign up }\end{array}$ & Sesuai \\
\hline
\end{tabular}

\subsubsection{Halaman Sign Up}

\begin{tabular}{|c|c|c|c|c|}
\hline $\begin{array}{l}\text { No } \\
\text { - }\end{array}$ & $\begin{array}{l}\text { Skenari } \\
\text { o } \\
\text { Penguji } \\
\text { an }\end{array}$ & $\begin{array}{l}\text { Hasil yang } \\
\text { Diharapka } \\
\text { n }\end{array}$ & $\begin{array}{l}\text { Hasil } \\
\text { yang } \\
\text { Didapatk } \\
\text { an }\end{array}$ & $\begin{array}{l}\text { Temuan } \\
\text { Kesesuai } \\
\text { an }\end{array}$ \\
\hline 1. & $\begin{array}{l}\text { Pilih } \\
\text { combo } \\
\text { box jenis } \\
\text { akun }\end{array}$ & $\begin{array}{l}\text { Menampilk } \\
\text { an jenis } \\
\text { akun }\end{array}$ & $\begin{array}{l}\text { Tampil } \\
\text { jenis akun } \\
\text { yang } \\
\text { dipilih }\end{array}$ & Sesuai \\
\hline 2. & $\begin{array}{l}\text { Input } \\
\text { nama } \\
\text { lengkap }\end{array}$ & $\begin{array}{l}\text { Menampilk } \\
\text { an nama } \\
\text { lengkap }\end{array}$ & $\begin{array}{l}\text { Tampil } \\
\text { nama } \\
\text { lengkap } \\
\text { yang } \\
\text { sudah } \\
\text { diinput }\end{array}$ & Sesuai \\
\hline 3. & $\begin{array}{l}\text { Input } \\
\text { email }\end{array}$ & $\begin{array}{l}\text { Menampilk } \\
\text { an email }\end{array}$ & $\begin{array}{l}\text { Tampil } \\
\text { email } \\
\text { yang } \\
\text { sudah } \\
\text { diinput }\end{array}$ & Sesuai \\
\hline 4. & $\begin{array}{l}\text { Input } \\
\text { usernam } \\
\mathrm{e}\end{array}$ & $\begin{array}{l}\text { Menampilk } \\
\text { an } \\
\text { username }\end{array}$ & $\begin{array}{l}\text { Tampil } \\
\text { username } \\
\text { yang } \\
\text { sudah } \\
\text { diinput }\end{array}$ & Sesuai \\
\hline 5. & $\begin{array}{l}\text { Input } \\
\text { passwor } \\
\text { d }\end{array}$ & $\begin{array}{l}\text { Menampilk } \\
\text { an } \\
\text { password }\end{array}$ & $\begin{array}{l}\text { Tampil } \\
\text { password } \\
\text { yang } \\
\text { sudah } \\
\text { diinput }\end{array}$ & Sesuai \\
\hline 6. & $\begin{array}{l}\text { Klik } \\
\text { button } \\
\text { sign up }\end{array}$ & $\begin{array}{l}\text { Menyimpa } \\
\mathrm{n} \text { data sign } \\
\text { up ke data } \\
\text { base dan } \\
\text { menampilk } \\
\text { an halaman } \\
\text { log in }\end{array}$ & $\begin{array}{l}\text { Data } \\
\text { tersimpan } \\
\text { pada } \\
\text { database } \\
\text { dan tampil } \\
\text { halaman } \\
\text { log in }\end{array}$ & Sesuai \\
\hline 7. & $\begin{array}{l}\text { Klik link } \\
\log \text { in }\end{array}$ & $\begin{array}{l}\text { Menampilk } \\
\text { an halaman } \\
\text { log in }\end{array}$ & $\begin{array}{l}\text { Tampil } \\
\text { halaman } \\
\text { log in }\end{array}$ & Sesuai \\
\hline 8. & $\begin{array}{l}\text { Klik nav } \\
\text { bar } \\
\text { home }\end{array}$ & $\begin{array}{l}\text { Menampilk } \\
\text { an halaman } \\
\text { home }\end{array}$ & $\begin{array}{l}\text { Tampil } \\
\text { halaman } \\
\text { home }\end{array}$ & Sesuai \\
\hline 9. & $\begin{array}{l}\text { Klik nav } \\
\text { bar log } \\
\text { in }\end{array}$ & $\begin{array}{l}\text { Menampilk } \\
\text { an halaman } \\
\text { log in }\end{array}$ & $\begin{array}{l}\text { Tampil } \\
\text { halaman } \\
\text { log in }\end{array}$ & Sesuai \\
\hline
\end{tabular}

\subsubsection{Halaman Home Turis}

\begin{tabular}{|c|l|l|l|l|}
\hline $\begin{array}{l}\text { No } \\
\cdot\end{array}$ & $\begin{array}{l}\text { Skenari } \\
\text { o } \\
\text { Penguji } \\
\text { an }\end{array}$ & $\begin{array}{l}\text { Hasil yang } \\
\text { Diharapka } \\
\text { n }\end{array}$ & $\begin{array}{l}\text { Hasil } \\
\text { yang } \\
\text { Didapatk } \\
\text { an }\end{array}$ & $\begin{array}{l}\text { Temuan } \\
\text { Kesesuai } \\
\text { an }\end{array}$ \\
\hline 1. & $\begin{array}{l}\text { Klik link } \\
\text { profile }\end{array}$ & $\begin{array}{l}\text { Menampilk } \\
\text { an halaman } \\
\text { profile }\end{array}$ & $\begin{array}{l}\text { Tampil } \\
\text { halaman } \\
\text { profile }\end{array}$ & Sesuai \\
\hline 2. & $\begin{array}{l}\text { Klik link } \\
\text { lokasi } \\
\text { temukan } \\
\text { perjalana } \\
\text { n }\end{array}$ & $\begin{array}{l}\text { Menampilk } \\
\text { an halaman } \\
\text { temukan } \\
\text { perjalanan }\end{array}$ & $\begin{array}{l}\text { Tampil } \\
\text { halaman } \\
\text { temukan } \\
\text { perjalanan }\end{array}$ & Sesuai \\
\hline 3. & $\begin{array}{l}\text { Klik link } \\
\text { message }\end{array}$ & $\begin{array}{l}\text { Menampilk } \\
\text { an halaman } \\
\text { message }\end{array}$ & $\begin{array}{l}\text { Tampil } \\
\text { halaman } \\
\text { message }\end{array}$ & Sesuai \\
\hline 4. & $\begin{array}{l}\text { Klik } \\
\text { marker } \\
\text { pada } \\
\text { maps }\end{array}$ & $\begin{array}{l}\text { Menampilk } \\
\text { an nama } \\
\text { lokasi dan } \\
\text { alamat }\end{array}$ & $\begin{array}{l}\text { Tampil } \\
\text { nama } \\
\text { lokasi dan } \\
\text { alamat }\end{array}$ & Sesuai \\
\hline
\end{tabular}




\subsubsection{Halaman Home Tour Guide}

\begin{tabular}{|c|l|l|l|l|}
\hline $\begin{array}{l}\text { No } \\
\cdot\end{array}$ & $\begin{array}{l}\text { Skenari } \\
\text { o } \\
\text { Penguji } \\
\text { an }\end{array}$ & $\begin{array}{l}\text { Hasil yang } \\
\text { Diharapka } \\
\text { n }\end{array}$ & $\begin{array}{l}\text { Hasil } \\
\text { yang } \\
\text { Didapatk } \\
\text { an }\end{array}$ & $\begin{array}{l}\text { Temuan } \\
\text { Kesesuai } \\
\text { an }\end{array}$ \\
\hline 1. & $\begin{array}{l}\text { Klik link } \\
\text { profile }\end{array}$ & $\begin{array}{l}\text { Menampilk } \\
\text { an halaman } \\
\text { profile }\end{array}$ & $\begin{array}{l}\text { Tampil } \\
\text { halaman } \\
\text { profile }\end{array}$ & Sesuai \\
\hline 2. & $\begin{array}{l}\text { Klik link } \\
\text { lokasi } \\
\text { wisata } \\
\text { saya }\end{array}$ & $\begin{array}{l}\text { Menampilk } \\
\text { an halaman } \\
\text { lokasi } \\
\text { wisata saya }\end{array}$ & $\begin{array}{l}\text { Tampil } \\
\text { halaman } \\
\text { lokasi } \\
\text { wisata } \\
\text { saya }\end{array}$ & Sesuai \\
\hline 3. & $\begin{array}{l}\text { Klik link } \\
\text { message }\end{array}$ & $\begin{array}{l}\text { Menampilk } \\
\text { an halaman } \\
\text { message }\end{array}$ & $\begin{array}{l}\text { Tampil } \\
\text { halaman } \\
\text { message }\end{array}$ & Sesuai \\
\hline 4. & $\begin{array}{l}\text { Klik } \\
\text { marker } \\
\text { pada } \\
\text { maps }\end{array}$ & $\begin{array}{l}\text { Menampilk } \\
\text { an nama } \\
\text { lokasi dan } \\
\text { alamat }\end{array}$ & $\begin{array}{l}\text { Tampil } \\
\text { nama } \\
\text { lokasi dan } \\
\text { alamat }\end{array}$ & Sesuai \\
\hline
\end{tabular}

\subsection{Tampilan Website}

\subsubsection{Tampilan Halaman Utama}

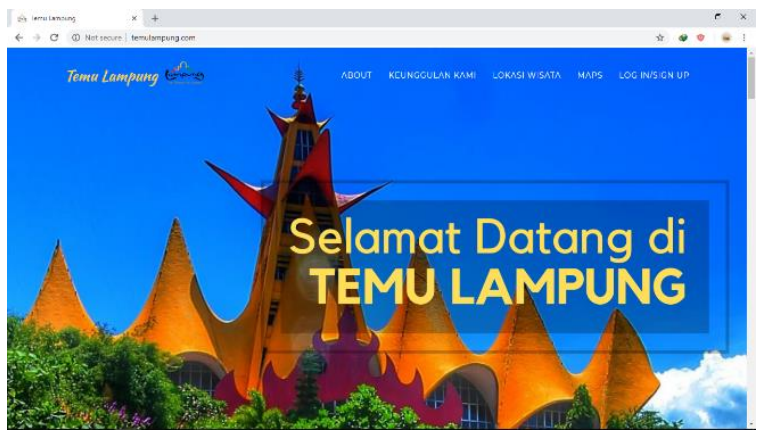

\subsubsection{Tampilan Halaman Log In}

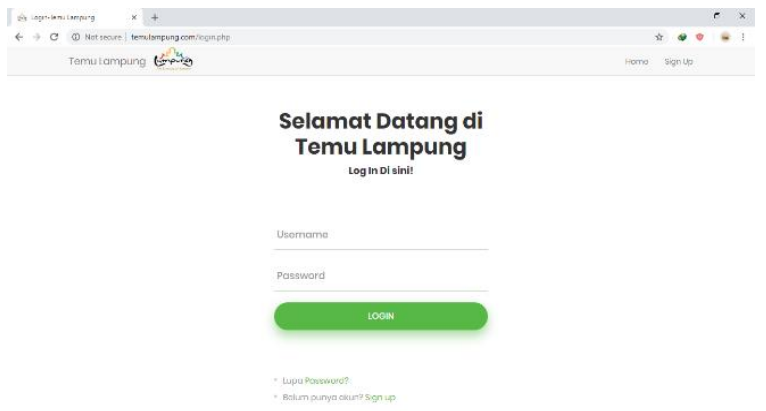

\subsubsection{Tampilan Halaman Sign Up}

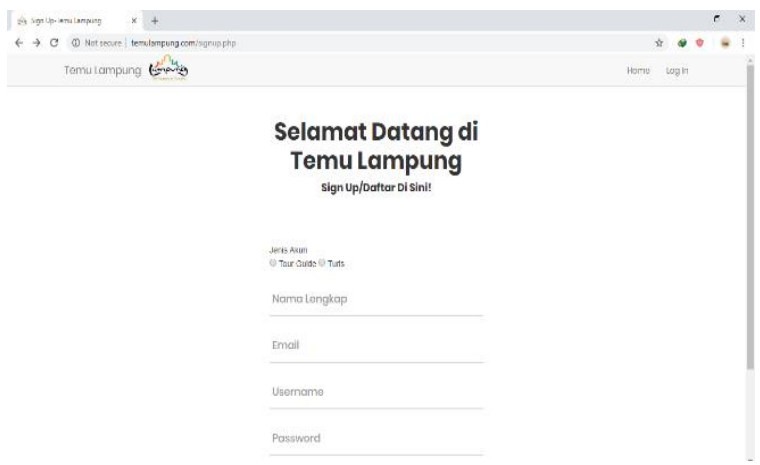

\subsubsection{Tampilan Halaman Home Turis}

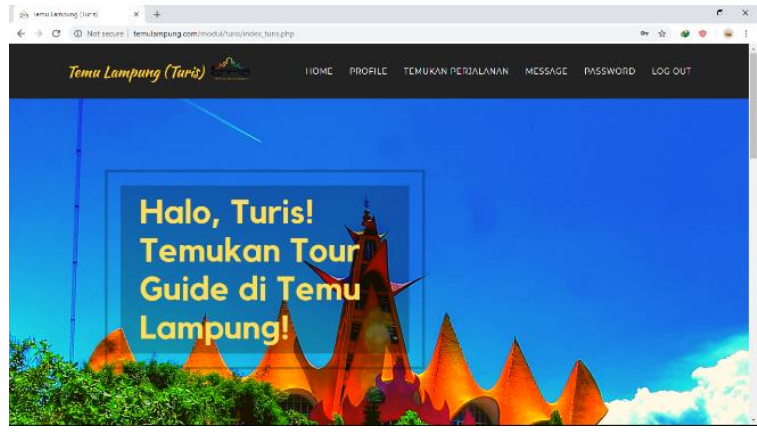

\subsubsection{Tampilan Halaman Home Tour Guide}

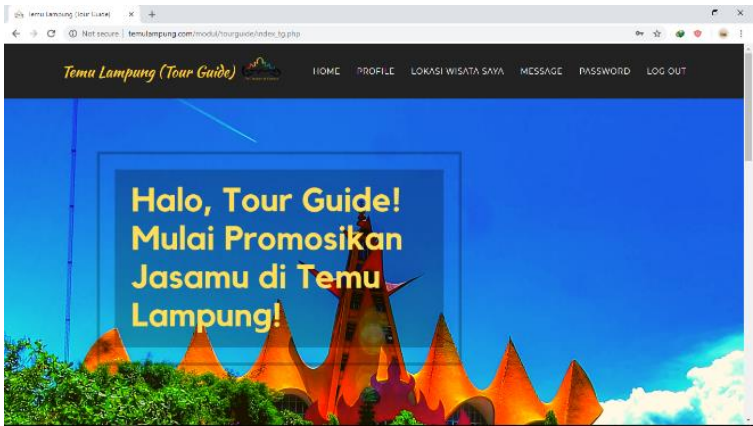

\section{Kesimpulan dan Saran}

\subsection{Kesimpulan}

Setelah melakukan penelitian, penulis mendapatkan beberapa kesimpulan:

a. Berdasarkan hasil kuisioner pre-test, para wisatawan merasa kurang informasi mengenai pariwisata di Lampung beserta pemandu wisatanya. Para wisatawan setuju dengan adanya pembangunan aplikasi berbasis sistem informasi geografis untuk mempermudah para wisatawan untuk mendapatkan informasi mengenai pariwisata di lampung beserta pemandu wisatanya.

b. Dalam penelitian ini menghasilkan sebuah website yang dapat memberikan informasi untuk mencari lokasi wisata di Lampung beserta dengan pemandu wisatanya.

c. Pada website yang telah dibangun, para pemandu wisata (tour guide) di Lampung dapat mempromosikan jasanya dengan cara membuat akun pada website Temu Lampung, lalu memilih lokasi wisata yang diketahuinya.

\subsection{Saran}

Sebagai bentuk penyempurnaan sistem website Temu Lampung dari penelitian ini, penulis ingin menyampaikan beberapa saran:

a. Website yang sudah dibuat masih jauh dari sempurna, diperlukan seorang pengembang 
berikutnya agar aplikasi yang sudah dibuat memiliki kelanjutan dan fitur-fitur baru.

b. Saat ini aplikasi masih berbasis website, diharapakan untuk pengembangan berikutnya dapat dibuat versi aplikasi mobile

\section{Daftar pustaka}

Ali Zaki, S. C. (2008). 36 Menit Belajar Komputer PHP dan MYSQL. Jakarta : Elex Media Komputindo.

Arief, M. (2011). Pemrogaman Web Dinamis Menggunakan PHP dan MySQL. Yogyakarta: Andi Publisher.
Ariani, F, Trisnasari, E. (2018). Aplikasi Berbasis Web Metode Servqual Untuk Mengukur Kepuasan Mahasiswa Terhadap Layanan Laboratorium Komputer Expert- Jurnal Management Sistem Informasi dan Teknologi Vol 8 No.2 Edisi Desember 2018. Hal : 57.

Jovan, F. (2007). Panduan Praktis Membuat WEB dengan PHP Untuk Pemula. Jakarta: Media Kita.

Komputer, W. (2010). Panduan Belajar MySQL Database Server. Jakarta: Mediakita.

Sugiyono, P. D. (2012). Metode Penelitian Pendidikan. Bandung: Alfabeta 
Expert - Jurnal Management Sistem Informasi dan Teknologi ISSN 2088-5555 